\title{
NEW INSIGHTS OF MAMMARY GLAND DURING DIFFERENT STAGES OF DEVELOPMENT
}

\author{
MANOJ KUMAR JENA ${ }^{1}$, ASHOK KUMAR MOHANTY2*
}

${ }^{1}$ Department of Biotechnology, Lovely Professional University, Phagwara - 144 411, Punjab, India. ${ }^{2}$ Animal Biotechnology Centre, National Dairy Research Institute, Karnal - 132 001, Haryana, India. Email: ashokmohanty1@gmail.com

Received: 17 June 2017, Revised and Accepted: 20 July 2017

ABSTRACT

Mammary gland is a unique organ with its function of milk synthesis, secretion, and involution to prepare the gland for subsequent lactation. The mammary epithelial cells proliferate, differentiate, undergo apoptosis, and tissue remodeling following a cyclic pathway in lactation - involution lactation cycle, thus fine tuning the molecular events through hormones, and regulatory molecules. Several studies are performed on the mammary gland development, lactogenesis, and involution process in molecular details. The developmental stages of mammary gland are embryonic, prepubertal, pubertal, pregnancy, lactation, and involution. Major developmental processes occur after puberty with hormones and growth factors playing crucial role. The two major pathways such as Janus kinases-signal transducer and activator of transcription pathway and PI3K-Akt pathway play a major role in maintaining the lactation. The involution process is a well-orchestrated event involving several signaling molecules and making the gland ready for subsequent lactation. The review focuses on findings with molecular details of different stages of the mammary gland development and signaling pathways involved in lactation-involution cycle. Deep insight into the developmental stages of mammary gland will pave the way to understand mammary gland biology, apoptosis, oncogenesis, and it will help the researchers to use mammary gland as a model for research on various aspects.

Keywords: Mammary gland, Lactation, Involution, Apoptosis, Development.

(C) 2017 The Authors. Published by Innovare Academic Sciences Pvt Ltd. This is an open access article under the CC BY license (http://creativecommons. org/licenses/by/4. 0/) DOI: http://dx.doi.org/10.22159/ajpcr.2017.v10i11.20801.

\section{INTRODUCTION}

Mammary gland (modified sebaceous gland) is exocrine in nature and made up of branched network of ducts ending in alveoli [1]. This gland is an excellent system to study the molecular events occurring in proliferation and differentiation of cells as well as cancer cell development (oncogenesis) [2]. This organ is unique in the sense; it can involute and regain its shape in each pregnancy-lactation-involution cycle. Mammary gland development mainly occurs after birth regulated by peptide and steroid hormones [3]. A complex cross-talk exists among various proteins expressed in different stages (pregnancy, lactation, and involution) during the functional mammary gland development. Intensive efforts have been made to unravel the molecular mechanisms involved in lactogenesis, apoptosis of mammary epithelial cells (MECs), and organ remodeling [1,4-7]. A number of previous studies at transcriptome level have been performed on this aspect. For example, cDNA library prepared from pooled sample of bovine mammary tissues - with a number of ESTs, paved the way for functional genomics studies of mammary gland [8]. Similarly, DNA microarray study comparing gene expression profiles of lactating and non-lactating bovine mammary tissue revealed many novel and interesting differentially expressed genes such as cell cycle regulators, mediators of apoptosis, and oncogenes [9]. Microarray analysis of transcriptional changes during pregnancy cycle of mouse mammary gland with a focus on lactation-involution transition revealed putative roles of death receptors and immune mediators in post-lactational regression [10]. Involution is associated with an immune cascade and acute phase response genes such as LBP, CD14, and signal transducer and activator of transcription (STAT)3 [11]. The CCAAT/enhancer binding protein delta is a crucial regulator of pro-apoptotic gene expression positioned with STAT3 at upstream and several pro- and anti-apoptotic genes at downstream level. A number of differentially expressed genes were identified by microarray analysis to understand the molecular events during the transition from late pregnancy to lactation in the mammary gland of Holstein cows [12].

It is observed that milk composition varies with stage of lactation which is specific to each species [13]. Milk is rich source of bioactive peptides (derived from milk proteins) which have antioxidant and antibacterial property [14]. Thus, it is important to understand the molecular events occurring during lactation which will help to unravel more about the milk components. This review focuses on the molecular details of mammary gland development with latest findings on changes in the mammary gland during pregnancy and lactation. This will help the researchers to understand mammary gland biology and use this organ as a model for different research area.

\section{FUNCTIONAL ANATOMY OF MAMMARY GLAND}

Mammary gland is a cutaneous gland such as sebaceous and sweat glands, producing milk to feed the young offspring in female. Histologically, it is a compound tubuloalveolar gland in the advanced mammals originating from the ectoderm and evolved from apocrine glands $[15,16]$. Bovine mammary gland is composed of two halves separated by the median suspensory ligament which primarily supports the udder along with the lateral suspensory ligament. Blood supply is mainly through the external pudendal artery, and venous drainage through the venous circle located at the base of the abdominal wall [16]. Mammary gland is made up of a branching network of ducts that end in alveoli. Alveoli are the basic functional units of the milking mammary gland and are grouped as lobules which connect to the collecting duct system. Mammary gland is a complex secretory organ with number of cell types: Epithelial cells (form the ductal network); adipocytes (constitute the fat pad); vascular endothelial cells (form blood vessels); stromal cells, including fibroblasts; and different immune cells [17]. The epithelial cells are of two types: Luminal and basal. Luminal epithelia form alveoli and duct system, whereas the basal one form myoepithelial cells involved in milk ejection.

\section{DEVELOPMENT OF MAMMARY GLAND}

Hormones play significant role in mammary gland development through distinct stages (Fig. 1). The mammary gland mainly consists of fat and connective tissue before puberty, and there is moderate elongation of epithelia into the fat pad which is not hormone-dependent. Ovarian steroid hormones stimulate the extension, and branching of ducts after 


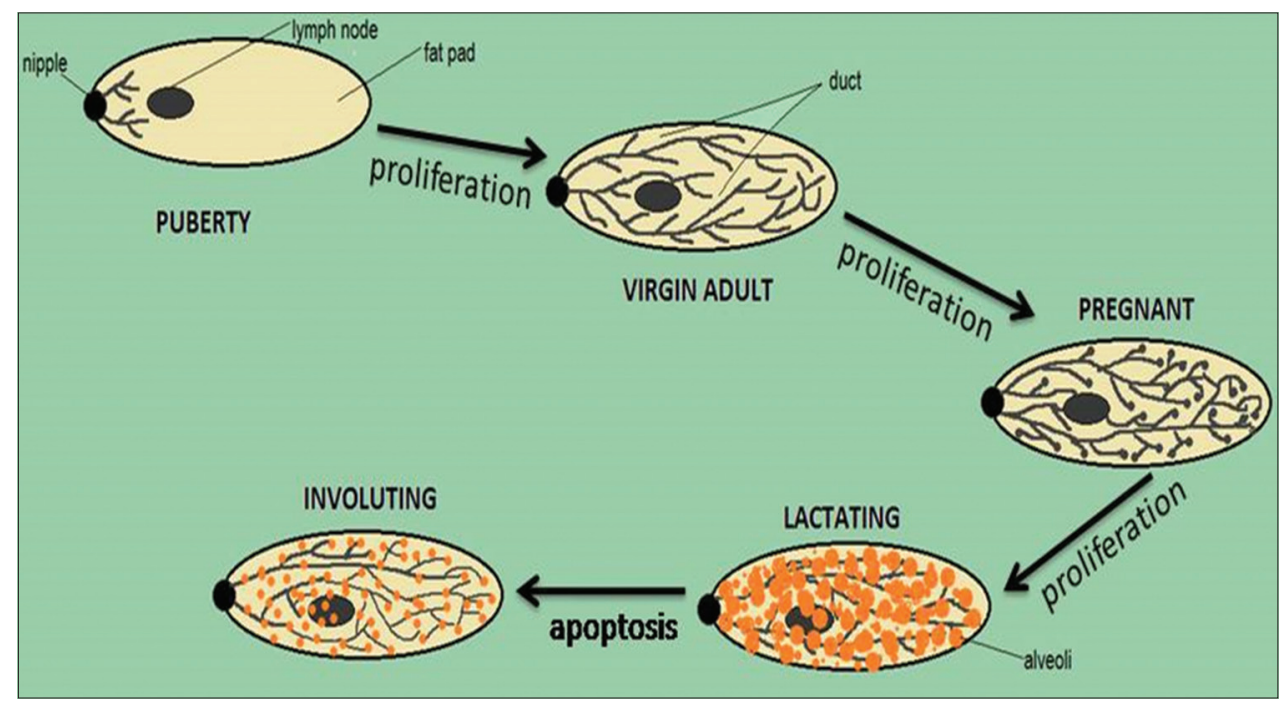

Fig. 1: A schematic overview of post-natal mammary gland development in mouse (redrawn from Andrechek et al. [18])

puberty is attained. The whole fat pad is occupied by the ducts due to accelerated mitosis of epithelial cells. Further branching occurs in pregnancy forming the lobules. Functional differentiation of epithelia leads to milk secretion (lactation) after parturition. Involution stage follows when milk suckling ceases, where epithelial cell apoptosis leads to mammary gland regression. Further, tissue remodeling occurs leaving the mammary gland as of a virgin female. Hence, mammary gland is the appropriate system for study of organogenesis, cell differentiation, apoptosis, and oncogenesis.

\section{Mammary gland development in embryonic stage}

The thickening of the embryonic skin cells (ectoderm) in ventral side gives rise to mammary band, as the first sign of gland development [19]. The mammary band subsequently converts to streak, line, crest, hillock, and mammary bud. Mammary gland of all species arises from the bud. Each mammary bud differentiates to the primary sprout which subsequently canalize at distal end to give rise to gland cistern. Further, branching of primary sprout forms the secondary sprouts which develop into mammary ducts. The fatty pad develops from mesoderm during embryonic stage. Mammary lines (milk lines) appearing on 10.5 day (E10.5) embryo is the first sign of mammary gland development in both male and female embryos of mouse. These lines (multilayered ectoderm) give rise to buds on ventral side of embryo extended from the forelimb to hindlimb in anteroposterior direction. It is suggested that epithelial placodes are formed through migration and coalescence of ectodermal cells among mammary line [20]. Initiation of mammary bud outgrowth and nipple formation seems to depend on interplay of some proteins such as parathyroid hormone-related protein (PTHrP), fibroblast growth factor 10 (FGF10), and bone morphogenetic protein 4 (BMP4) expressed in the placodes [21] during embryonic stage. PTHrP expression from MECs occur by E11.0 and BMP4 expression occurs both from epithelial and mesenchymal cells between E11.5 and E14.5. Mammary bud and nipple development occur by interaction of PTHrP and BMP signaling. The PTHrP enhances BMP receptor BMPR1A expression in mesenchymal cells which interacts with BMP4. The BMP4 signaling induces epithelial outgrowth, enhances MSX2 (msh homeobox2) expression thus inhibiting formation of hair follicles within the nipple sheath. At E16.0, the mammary sprouts branch out to form tree-like gland with 10-15 small branches.

\section{Mammary gland development from puberty to conception}

Mammary gland development from birth to puberty is isometric (i.e., similar to the growth rate of the body) in most of the mammals, whereas allometric growth occurs after puberty is attained. Mouse mammary gland development at puberty is studied more thoroughly. The tips of the ducts called terminal end buds (TEBs) are club-shaped structure having two types of cells: Outer cap cell layer and inner core of body cells (multilayered). These TEBs proliferate resulting in duct elongation due to rise of estrogen at puberty. The TEBs bifurcate the ducts and form branches. Apoptosis of body cells lead to lumen formation [22] and by 10-12 week of age, TEBs disappear as fat pad limits are reached. The homeostatic event of side branching and cell death is a crucial phenomenon in each estrous cycle after puberty. Interplay of some regulatory molecules influences the ductal branching and elongation [23]. The transcription factor GATA-3 in body cells induces estrogen receptor $\alpha(E R \alpha)$ expressing cell lineage making the cells more receptive to estrogen. The GATA-3 - ER $\alpha$ cross-talk is mediated by another protein FOXA1 [24]. The protein sharpin (a multifunctional protein) has a role in the mammary gland development as evidenced from studies in mice where targeted deletion of sharpin gene caused reduction of ductal branching during puberty [25]. Sharpin controls extracellular matrix (ECM) organization of stroma during branching morphogenesis. Estrogen plays crucial role in branching morphogenesis in virgin gland mediating its function through two receptors: ER $\alpha$ and ER $\beta$. The ER $\alpha$-mediated action also induces alveologenesis during late pregnancy and lactation [26]. The apoptotic epithelial cells must be removed promptly during postlactational regression which is mediated by the protein MFGE8, and this protein is also crucial in branching morphogenesis [27]. The MFGE8 is produced both by luminal and basal epithelial (myoepithelial) cells. Major hormonal changes precede the puberty with follicle stimulating hormone and luteinizing hormone secreted from anterior pituitary gland play crucial role. These hormones stimulate ovary to synthesize the steroid hormones estrogen and progesterone. These hormones influence ovarian cycle with estrogen dominating during follicular phase (follicle growth occurs) whereas progesterone during the luteal phase (corpus luteum [CL] development). The duct lengthening and branching is also in harmony with two more anterior pituitary hormones such as prolactin and somatotropin. Estrogen stimulates epithelial cell division in TEB tips leading to duct lengthening and branching, whereas progesterone induces duct and ductile cell proliferation leading to duct widening. Progesterone and ERs appear in mammary gland at puberty. Functional CL is observed in species such as cattle, buffalo, sheep, goat, horse, and human which show long cycle where the CL produces progesterone during luteal phase.

\section{Mammogenesis during pregnancy}

Mammary gland growth occurs significantly during pregnancy where the growth rate is slow at the initial stage but increases as the pregnancy proceeds. Mammogenesis progresses in exponential manner throughout pregnancy in most of the species. Estrogen and progesterone are the major hormones for optimal mammary growth. 
During the advancement of pregnancy, the fatty tissue is replaced by ducts and ductules, alveoli, blood vessels, etc. It is clear that in all species, alveoli development does not occur before pregnancy. The lobuloalveolar development requires both estrogen and progesterone that is why this growth pattern is not found in estrous cycle where surge of either estrogen or progesterone occurs at a time. Progesterone level remains high throughout pregnancy, whereas estrogen level is high in second phase. This is the reason of most of the growth occurs in 2nd phase. Duct and lobule formation predominates in first half; and lobuloalveolar growth predominates in second half. The exponential growth does not stop immediately in beginning of lactation. There is accumulation of milk in the alveoli, loss of secretory cell occurs with simultaneous regeneration of epithelial cells throughout lactation. The ERs such as ER $\alpha$ and $\mathrm{ER}_{\beta}$ play distinct roles in normal mammary gland development as well as in development of breast cancer [28]. There is every possibility of increased risk of breast cancer due to increased estrogen level [29] which shows the necessity of fine tuning of hormone level for normal mammary gland development. Coordinated action of prolactin and growth hormone (GH) also cause mammogenesis in synergy with estrogen and progesterone. Another hormone called placental lactogen (secreted from placenta) has prolactin and GH-like activity. The hormone relaxin plays a role in preparing the reproductive tract in late pregnancy for the parturition process [30].

The mammary gland development in human and mice are more or less similar. Progesterone causes alveologenesis and alveoli differentiation along with prolactin. Evidences for these functions came from the experiments of Brisken et al. [31] and Ormandy et al. [32] who observed the absence of progesterone and prolactin receptor leads to loss of formation of side branching, alveoli formation, and differentiation. The origin of alveolar luminal and basal cells is still not clear. Studies reveal luminal and basal cells are derived from bipotent ductal progenitors, whereas other evidences show existence of separate duct-limited and lobule-limited progenitors in mouse and rat [33]. The signaling pathways involved in Th-cell lineage commitment [23,24,34] also play a role in mammary lineage development, although hormones primarily regulate mammary gland differentiation [35] temporally. The transcription factor GATA3 is also equally important in mammary lineage development. GATA3 induces self-renewal of mammary stem cells which asymmetrically divide to produce daughter cells, and these daughter cells give rise to either basal or luminal progenitor lineage cells. The cytokines interleukin (IL) 4 and IL13 induce GATA3 and C-MAF expression which further facilitate differentiation of alveolar cells [34].

\section{Mammary gland during lactation}

During pregnancy, elevated secretion of estradioland progesteronedrives the allometric mammary growth, which continues in most species after parturition for a variable period. The galactopoietic hormones such as $\mathrm{GH}$ and prolactin play major role in mammary gland function. Prolactin regulates different physiological processes such as lactation, immunity, reproductive function, and electrolyte balance. [36]. It maintains the lactation by acting through two signaling pathways such as Janus kinases (JAK)2-STAT5 pathway and PI3K-AKT pathway $[37,38]$ which mediate milk protein, lipids, and lactose formation [39]. Prolactin binds to prolactin receptor on MECs which activates the JAK-STAT signaling. In this process, the transcription factor STAT5 is phosphorylated by JAK2, and subsequently, the phosphorylated STAT5 enters the nucleus and targets milk producing genes by regulating their transcription [35]. Milk protein, lipids, and lactose formation are mediated by the two signaling pathways mentioned. Phospho-STAT5 regulates transcription of milk protein genes, whereas AKT regulates lactose and lipid synthesis, glucose transport, and milk protein translation. Studies on PI3K-AKT activation in virgin mice revealed rapid activation of STAT5, terminal differentiation of MECs, and ultimately milk production mediated by prolactin [40]. The hormone GH is known to increase the uptake of nutrients used for milk synthesis. GH acts indirectly on MEC, through the production of insulin like growth factor (IGF)-I, to stimulate lipid synthesis by maintaining activation of lipoprotein lipase and acetyl-CoA carboxylase [41]. Cortisol is released during milking and is required to maintain secretory activation of cells [42]. Local mammary factors also play a role in maintenance of milk secretion, as milk removal is required for continued milk secretion. Milk secretion is regulated in many species by a factor called feedback inhibitor of lactation [43], which blocks constitutive milk secretion through concentration-dependent manner in autocrine fashion [44]. There is a gradual decrease in MEC number after peak lactation leading to decreased milk yield [45], and apoptosis is the major event reducing the cell number [46]. The protein glutaredoxin-3 is playing a crucial role in mammary gland development during pregnancy and lactation [47]. It promotes the lobuloalveolar development by indirectly reducing the cellular ROS (reactive oxygen species) level and enhancing the expression of milk protein genes as well as proliferative genes for alveoli development. Another protein XBP1 (transcription factor) regulates biosynthesis in MECs by influencing epithelial expansion and formation of estrogen in MECs [48].

\section{Mammary gland during involution}

The involution process is characterized by massive apoptosis of secretory MECs along with remodeling of ECM and fat pad regeneration through adipogenesis. An inflammatory cascade and acute phase response are associated with these events. Various genes and number of signaling pathways are involved regulating the involution through immune response, apoptosis, phagocytosis, and tissue remodeling [7]. Involution takes place in two discrete phases. The first phase lasts for approximately $48 \mathrm{hrs}$ in the mouse and is reversible, whereas in the second phase, a remodeling program is initiated that shapes the gland to a non-pregnant state [6]. The first phase is characterized by the appearance of shed, dying cells within lumen of alveoli which become expanded by the accumulation of milk. At this time, infiltration by neutrophils also occurs. Local factors regulate the first phase, and there is no role of circulating hormones [49,50]. In the second phase, cell death is accompanied by upregulation of matrix metalloproteinases (MMPs) which are important in the remodeling of the surrounding stroma, accompanied by adipocyte refilling, influx of macrophages, and active plasma kallikrein formation that regulates adipocyte differentiation and stromal remodeling [51]. The MMPs such as MMP14 and MMP15 regulate adipocyte differentiation with promoting deposition of white fat and brown fat, respectively [52]. Circulating factors regulate this phase and it is observed systemic administration of glucocorticoids [6,53] halts this phase which may act through the maintenance of tight junctions [54]. Increased expression of tissue inhibitors of metalloproteinases leads to blocking of MMP function in the first phase [55]. Milk stasis seems to be the primary trigger of involution and cell death [49]. There have been several suggestions as to how milk stasis might initiate involution including mechanical stretch of the alveolar epithelium due to milk retention in the lumen [56] or the buildup of secreted factors in the milk. The plasma membrane calcium - ATPase 2 (PMCA2) which has major role of transporting milk calcium (60-70\% of milk calcium) gets upregulated during lactation and also dramatically downregulated during involution. The PMCA2 level was shown to be regulated by changes in the shape of MECs [56]. Secreted factors such as LIF [57-59], serotonin [60], and transforming growth factor- $\beta 3$ (TGF- $\beta$ 3) [61] are also important in inducing cell death as mice deficient for LIF exhibited delayed involution while directed expression of TGF- $\beta 3$ in the alveolar epithelium of lactating mice induced apoptosis without tissue remodeling. Serotonin suppresses $\beta$-casein gene expression and causes mammary alveoli to shrink. The most dramatic delay in involution is seen when the transcription factor STAT3 is conditionally deleted in mammary epithelium. Cell death and tissue remodeling are completely abrogated in the absence of STAT3 [62], and the reversible phase of involution is extended until at least 6 days post-forced involution [63]. A similar delay is observed when the upstream regulator of the nuclear factor kappa B pathways, IKK $\beta$, is conditionally deleted [64] suggesting that crosstalk between these signaling pathways is required for the process of involution and each pathway is necessary, but neither is sufficient, to trigger cell death. STAT3 which is a member of STAT family plays major role (Fig. 2) in the involution process [65]. This protein gets activated in the first phase whereas STAT5a (higher level in lactation) 


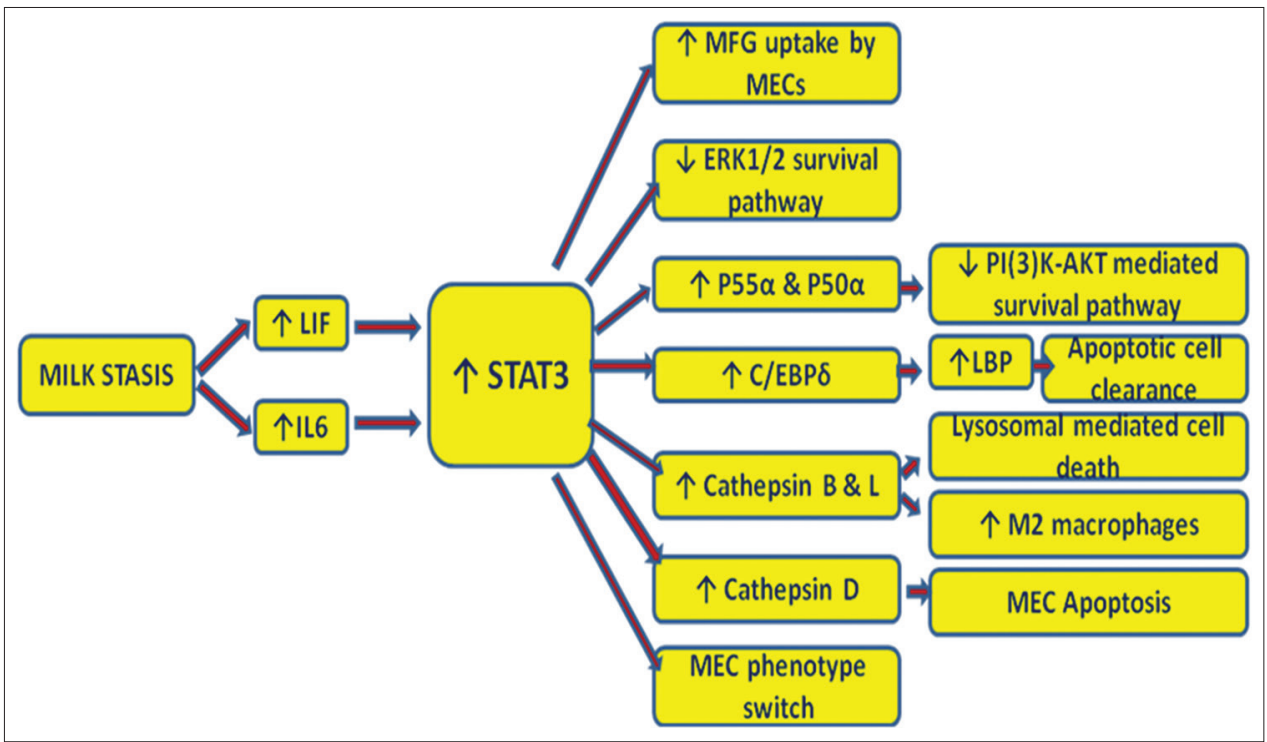

Fig. 2: The signal transducer and activator of transcription 3 protein regulating the pathways and other molecules during involution

activity decreases. Components of apoptosis pathways have also been implicated including death receptor ligands such as FasL [66] which is important for apoptosis at $24 \mathrm{hrs}$ involution, tumor necrosis factoralpha-related apoptosis-inducing ligand, which is upregulated by IL10 during involution [67]. Members of the Bcl2 family of apoptosis regulators such as Bax, promotes cell death as deletion of Bax results in a modest decrease in apoptosis in the first phase and $\mathrm{Bcl} 2$, which promotes survival of the epithelium in a gain-of-function transgenic model [68]. Loss of the antiapoptotic Bcl-xL accelerates involution [69]. During the second phase of involution, cell death occurs alongside tissue remodeling and it is more difficult to discern delayed involution phenotypes. However, removal of dead cells and residual milk is critical for involution to proceed and subsequent successful lactation as reduced phagocytosis in the absence of the bridging molecule MFGE8 results in inflammation and tissue scarring and subsequent failed lactation $[70,71]$.

Mammary stem cells are pluripotent in nature playing a role in tissue repair and regeneration [72]. Studies suggest the origin of mammary stem cells in adult stage is from the proliferating embryonic stem cells of the mammary gland during embryogenesis which has become quiescent in the adult stage [73].

\section{GROWTH FACTORS AND CYTOKINES INVOLVED}

The growth factors and cytokines play a crucial role in the normal mammary gland development in each stage beginning from embryogenesis. The growth factors also cross talk with hormones to regulate gland development. The growth factors such as epidermal growth factors (EGFs) and their receptors, FGFs and their receptors, and IGFs and their receptors have direct involvement in mammary gland development [74]. These growth factors play specific role whereas steroid hormones, prolactin, and GH are major regulators of mammary growth and differentiation. Increased expression of FGFs such as FGF1, $2,4,7$, and 10 along with FGFR1 and FGFR2 is observed during ductal branching [75]. The TGF- $\beta$ family members play an important role in ductal differentiation and branching morphogenesis; besides their involvement in malignant ductal tissue patterning [76]. It is observed that the protein termed CUB and zona pellucida-like domain-containing protein 1 mediates its function to control gland development through JAK2-STAT5 pathway during conception [77]. The IGF1 is essential for lobule and alveoli development [78]. In all the processes of ductal branching, alveolar differentiation, and lactation number of EGF family ligands and their receptors are expressed [79]. The STAT protein family includes the intracellular transcription factors which are mainly activated by receptor associated JAK. There are 7 STAT proteins (STAT1, $2,3,4,5 \mathrm{~A}, 5 \mathrm{~B}$, and 6 ) identified in mammalian system and out of which STAT1, 3, 5, and 6 play major role in mammary gland development [74]. STATs have no significant role in mammary gland development during the embryonic stage. Specific time windows persist for STAT activity in adult mammary gland. Constitutive expression of STAT1 and 3 is observed in adult mammary gland; however, the active state of STAT1 (tyrosine phosphorylated) is found in virgin gland and in late stage of involution (after mammary gland remodeling); whereas STAT3 is active during involution [80]. Apoptosis in mammary gland is primarily mediated by STAT3, and LIF is the physiological activator of STAT3 [58]. The STAT6 dominates during pregnancy whereas STAT5 is active in lactation. The STATs become active as dimers by the JAKs and then enter into the nucleus where they bind to motif TTCCNGGAA (palindromic) and induce target gene transcription. Cytokines are the soluble proteins playing major role in cell-cell interaction by inducing receptor and coreceptor expression. Cytokine receptors depend on JAK kinases [81] as they lack intrinsic kinase property. The ligands that bind to receptor families are mainly interleukins, LIF, and prolactin which influence the mammary gland development and lactation. The atypical chemokine receptor ACKR2 is found to be involved in mammary gland development (branching morphogenesis) besides its primary function of regulation of macrophage dynamics in lymph vessel development [82]. The non-canonical WNT signaling pathway also regulates MEC growth and branching morphogenesis where WNT5A enhances growth of epithelium and WNT5B inhibits mammary proliferation [83].

\section{CONCLUSION}

The complex phenomena that occur in the mammary gland during its development makes the researchers interesting to study the gland in details to excel our research on organogenesis, apoptosis, and oncology. This unique organ provides ample of informations on developmental biology, and events occurring during pregnancy and lactation. Lactogenesis is a major event in mammary gland, and its study will facilitate for enhancing milk production in livestock both qualitative as well as quantitative aspects. Present day research on the production of transgenic animals secreting pharmaceuticals in milk is of great interest, and this review will provide researchers comprehensive informations on mammary gland development for the future study.

\section{REFERENCES}

1. Jena MK, Janjanam J, Naru J, Kumar S, Kumar S, Singh S, et al. DIGE based proteome analysis of mammary gland tissue in water 
buffalo (Bubalus bubalis): Lactating vis-a-vis heifer. J Proteomics 2015;119:100-11.

2. Desrivières $\mathrm{S}$, Kuhn $\mathrm{K}$, Müller $\mathrm{J}$, Gläser $\mathrm{M}$, Laria NC, Korder $\mathrm{J}$, et al. Comparison of the nuclear proteomes of mammary epithelial cells at different stages of functional differentiation. Proteomics 2007;7(12):2019-37.

3. Hennighausen L, Robinson GW. Signaling pathways in mammary gland development. Dev Cell 2001;1(4):467-75.

4. Janjanam J, Jamwal M, Singh S, Kumar S, Panigrahi AK, Hariprasad G, et al. Proteome analysis of functionally differentiated bovine (Bos indicus) mammary epithelial cells isolated from milk. Proteomics 2013;13(21):3189-204

5. Brisken C, Rajaram RD. Alveolar and lactogenic differentiation. J Mammary Gland Biol Neoplasia 2006;11(3-4):239-48.

6. Lund LR, Rømer J, Thomasset N, Solberg H, Pyke C, Bissell MJ, et al. Two distinct phases of apoptosis in mammary gland involution: Proteinase-independent and-dependent pathways. Development 1996;122(1):181-93

7. Watson CJ, Kreuzaler PA. Remodeling mechanisms of the mammary gland during involution. Int J Dev Biol 2011;55(7-9):757-62.

8. Sonstegard TS, Capuco AV, White J, Van Tassell CP, Connor EE, Cho J, et al. Analysis of bovine mammary gland EST and functional annotation of the Bos taurus gene index. Mamm Genome 2002;13(7):373-9.

9. Suchyta SP, Sipkovsky S, Halgren RG, Kruska R, Elftman M, Weber-Nielsen $\mathrm{M}$, et al. Bovine mammary gene expression profiling using a cDNA microarray enhanced for mammary-specific transcripts. Physiol Genomics 2003;16(1):8-18.

10. Clarkson RW, Wayland MT, Lee J, Freeman T, Watson CJ. Gene expression profiling of mammary gland development reveals putative roles for death receptors and immune mediators in post-lactational regression. Breast Cancer Res 2004;6(2):R92-109.

11. Stein T, Morris JS, Davies CR, Weber-Hall SJ, Duffy MA, Heath VJ, et al. Involution of the mouse mammary gland is associated with an immune cascade and an acute-phase response, involving LBP, CD14 and STAT3. Breast Cancer Res 2004;6(2):R75-91.

12. Finucane KA, McFadden TB, Bond JP, Kennelly JJ. Zhao FQ. Onset of lactation in the bovine mammary gland: Gene expression profiling indicates a strong inhibition of gene expression in cell proliferation. Funct Integr Genomics 2008;8(3):251-64.

13. Hartmann P, Cregan M. Lactogenesis and the effects of insulin-dependent diabetes mellitus and prematurity. J Nutr 2001;131(11):3016S-20.

14. Praveesh BV, Angayarkanni J, Palaniswamy M. Antihypertensive and anticancer effect of cow milk fermented by Lactobacillus plantarum and Lactobacillus casei. Int J Pharm Pharm Sci 2011;3 Suppl 5:452-6.

15. Oftedal OT. The mammary gland and its origin during synapsid evolution. J Mammary Gland Biol Neoplasia 2002;7(3):225-52.

16. Husveth F. Physiological and Reproductional Aspects of Animal Production. Debrecen, Hungary: Debreceni Egyetem; 2011.

17. Watson CJ, Khaled WT. Mammary development in the embryo and adult: A journey of morphogenesis and commitment. Development 2008;135(6):995-1003

18. Andrechek ER, Mori S, Rempel RE, Chang JT, Nevins JR. Patterns of cell signaling pathway activation that characterize mammary development. Development 2008;135(14):2403-13.

19. Larson BL, editor. Lactation: A Comprehensive Treatise. Vol. 1-3. New York: Academic; 1978.

20. Veltmaat JM, Van Veelen W, Thiery JP, Bellusci S. Identification of the mammary line in mouse by Wnt10b expression. Dev Dyn 2004;229(2):349-56

21. Hens JR, Dann P, Zhang JP, Harris S, Robinson GW, Wysolmerski J. BMP4 and PTHrP interact to stimulate ductal outgrowth during embryonic mammary development and to inhibit hair follicle induction. Development 2007;134(6):1221-30.

22. Humphreys RC, Krajewska M, Krnacik S, Jaeger R, Weiher H, Krajewski S, et al. Apoptosis in the terminal end bud of the murine mammary gland: A mechanism of ductal morphogenesis. Development 1996;122(12):4013-22

23. Asselin-Labat ML, Sutherland KD, Barker H, Thomas R, Shackleton M, Forrest NC, et al. Gata-3 is an essential regulator of mammarygland morphogenesis and luminal-cell differentiation. Nat Cell Biol 2007;9(2):201-9.

24. Kouros-Mehr H, Slorach EM, Sternlicht MD, Werb Z. GATA-3 maintains the differentiation of the luminal cell fate in the mammary gland. Cell 2006;127(5):1041-55.

25. Peuhu E, Kaukonen R, Lerche M, Saari M, Guzmán C, Rantakari P, et al. SHARPIN regulates collagen architecture and ductal outgrowth in the developing mouse mammary gland. EMBO J 2017;36(2):165-82.
26. Feng Y, Manka D, Wagner KU, Khan SA. Estrogen receptoralpha expression in the mammary epithelium is required for ductal and alveolar morphogenesis in mice. Proc Natl Acad Sci U S A 2007;104(37):14718-23

27. Ensslin MA, Shur BD. The EGF repeat and discoidin domain protein, SED1/MFG-E8, is required for mammary gland branching morphogenesis. Proc Natl Acad Sci U S A 2007;104(8):2715-20.

28. Mehta RG, Hawthorne M, Mehta RR, Torres KE, Peng $\mathrm{X}$, McCormick DL, et al. Differential roles of ER $\alpha$ and ER $\beta$ in normal and neoplastic development in the mouse mammary gland. PLoS One 2014;9(11):e113175

29. Lakshmi R, Vijayalakshmi S, Raju A, Joy TM. Assessment of various risk factors of breast cancer. Int J Pharm Pharm Sci 2013; 5 Suppl 4:675-8.

30. Wright LC, Anderson RR. Effect of relaxin on mammary growth in the hypophysectomized rat. Adv Exp Med Biol 1982;143:341-55.

31. Brisken C, Park S, Vass T, Lydon JP, O'Malley BW, Weinberg RA. A paracrine role for the epithelial progesterone receptor in mammary gland development. Proc Natl Acad Sci U S A 1998;95(9):5076-81.

32. Ormandy CJ, Camus A, Barra J, Damotte D, Lucas B, Buteau H, et al. Null mutation of the prolactin receptor gene produces multiple reproductive defects in the mouse. Genes Dev 1997;11(2):167-78.

33. Smith GH, BoulangerCA. Mammary epithelial stem cells: Transplantation and self-renewal analysis. Cell Prolif 2003;36 Suppl 1:3-15.

34. Khaled WT, Read EK, Nicholson SE, Baxter FO, Brennan AJ, Came PJ, et al. The IL-4/IL-13/Stat6 signalling pathway promotes luminal mammary epithelial cell development. Development 2007;134(15):2739-50

35. Hennighausen L, Robinson GW. Information networks in the mammary gland. Nat Rev Mol Cell Biol 2005;6(9):715-25.

36. Ben-Jonathan N, LaPensee CR, LaPensee EW. What can we learn from rodents about prolactin in humans? Endocr Rev 2008;29(1):1-41.

37. Acosta JJ, Munoz RM, Gonzalez L, Subtil-Rodriguez A, DominguezCaceres MA, Garcia-Martinez JM, et al. Src mediates prolactindependent proliferation of T47D and MCF7 cells via the activation of focal adhesion kinase/Erk1/2 and phosphatidyl inositol 3-kinase pathways. Mol Endocrinol 2003;17(11):2268-82

38. Chakravarti P, Henry MK, Quelle FW. Prolactin and heregulin override DNA damage-induced growth arrest and promote phosphatidylinositol-3 kinase-dependent proliferation in breast cancer cells. Int J Oncol 2005;26(2):509-14.

39. Anderson SM, Rudolph MC, McManaman JL, Neville MC. Key stages in mammary gland development. Secretory activation in the mammary gland: It's not just about milk protein synthesis! Breast Cancer Res 2007;9(1):204

40. Chen CC, Stairs DB, Boxer RB, Belka GK, Horseman ND, Alvarez JV, et al. Autocrine prolactin induced by the Pten-Akt pathway is required for lactation initiation and provides a direct link between the Akt and Stat5 pathways. Genes Dev 2012;26(19):2154-68.

41. Knight $\mathrm{CH}$. Overview of prolactin's role in farm animal lactation. Livest Prod Sci 2001;70(1-2):87-93.

42. Gorewit RC, Svennersten K, Butler WR, Uvnäs-Moberg K. Endocrine responses in cows milked by hand and machine. J Dairy Sci $1992 ; 75(2): 443-8$

43. Peaker M. Autocrine control of milk secretion: Development of the concept. Intercellular Signalling in the Mammary Gland. New York: Plenum Publishing Company; 1995. p. 193-202.

44. Rennison ME, Kerr M, Addey CV, Handel SE, Turner MD, Wilde CJ, et al. Inhibition of constitutive protein secretion from lactating mouse mammary epithelial cells by FIL (feedback inhibitor of lactation), a secreted milk protein. J Cell Sci 1993;106:641-8.

45. Wilde CJ, Knight CH. Metabolic adaptations in mammary gland during the declining phase of lactation. J Dairy Sci 1989;72(6):1679-92.

46. Quarrie LH, Addey CV, Wilde CJ. Local regulation of mammary apoptosis in the lactating goat. Biochem Soc Trans 1994;22(2):178S.

47. Pham K, Dong J, Jiang X, Qu Y, Yu H, Yang Y, et al. Loss of glutaredoxin 3 impedes mammary lobuloalveolar development during pregnancy and lactation. Am J Physiol Endocrinol Metab 2017;312(3):E136-49.

48. Davis KR, Giesy SL, Long Q, Krumm CS, Harvatine KJ, Boisclair YR. $\mathrm{XBP} 1$ regulates the biosynthetic capacity of the mammary gland during lactation by controlling epithelial expansion and endoplasmic reticulum formation. Endocrinology 2016;157(1):417-28.

49. Li M, Liu X, Robinson G, Bar-Peled U, Wagner KU, Young WS, et al. Mammary-derived signals activate programmed cell death during the first stage of mammary gland involution. Proc Natl Acad Sci U S A 1997;94(7):3425-30.

50. Marti A, Feng Z, Altermatt HJ, Jaggi R. Milk accumulation 
triggers apoptosis of mammary epithelial cells. Eur J Cell Biol 1997;73(2):158-65.

51. Lilla JN, Joshi RV, Craik CS, Werb Z. Active plasma kallikrein localizes to mast cells and regulates epithelial cell apoptosis, adipocyte differentiation, and stromal remodeling during mammary gland involution. J Biol Chem 2009;284(20):13792-803.

52. Feinberg TY, Rowe RG, Saunders TL, Weiss SJ. Functional roles of MMP14 and MMP15 in early postnatal mammary gland development. Development 2016;143(21):3956-68.

53. Feng Z, Marti A, Jehn B, Altermatt HJ, Chicaiza G, Jaggi R. Glucocorticoid and progesterone inhibit involution and programmed cell death in the mouse mammary gland. J Cell Biol 1995;131(4):1095-103.

54. Zettl KS, Sjaastad MD, Riskin PM, Parry G, Machen TE, Firestone GL. Glucocorticoid-induced formation of tight junctions in mouse mammary epithelial cells in vitro. Proc Natl Acad Sci U S A 1992;89(19):9069-73.

55. Green KA, Lund LR. ECM degrading proteases and tissue remodelling in the mammary gland. Bioessays 2005;27(9):894-903.

56. Quaglino A, Salierno M, Pellegrotti J, Rubinstein N, Kordon EC. Mechanical strain induces involution-associated events in mammary epithelial cells. BMC Cell Biol 2009;10:55

57. VanHouten J, Sullivan C, Bazinet C, Ryoo T, Camp R, Rimm DL, et al. PMCA2 regulates apoptosis during mammary gland involution and predicts outcome in breast cancer. Proc Natl Acad Sci U S A 2010;107(25):11405-10.

58. Kritikou EA, Sharkey A, Abell K, Came PJ, Anderson E, Clarkson RW, et al. A dual, non-redundant, role for LIF as a regulator of development and STAT3-mediated cell death in mammary gland. Development 2003;130(15):3459-68

59. Schere-Levy C, Buggiano V, Quaglino A, Gattelli A, Cirio MC, Piazzon I, et al. Leukemia inhibitory factor induces apoptosis of the mammary epithelial cells and participates in mouse mammary gland involution. Exp Cell Res 2003;282(1):35-47.

60. Matsuda M, Imaoka T, Vomachka AJ, Gudelsky GA, Hou Z, Mistry M, et al. Serotonin regulates mammary gland development via an autocrineparacrine loop. Dev Cell 2004;6(2):193-203.

61. Nguyen AV, Pollard JW. Transforming growth factor beta3 induces cell death during the first stage of mammary gland involution. Development 2000;127(14):3107-18

62. Chapman RS, Lourenco PC, Tonner E, Flint DJ, Selbert S, Takeda K, et al. Suppression of epithelial apoptosis and delayed mammary gland involution in mice with a conditional knockout of Stat3. Genes Dev 1999;13(19):2604-16.

63. Humphreys RC, Bierie B, Zhao L, Raz R, Levy D, Hennighausen L. Deletion of Stat3 blocks mammary gland involution and extends functional competence of the secretory epithelium in the absence of lactogenic stimuli. Endocrinology 2002;143(9):3641-50.

64. Baxter FO, Came PJ, Abell K, Kedjouar B, Huth M, Rajewsky K, et al. IKKbeta/2 induces TWEAK and apoptosis in mammary epithelial cells. Development 2006;133:3485-94

65. Haricharan S, Li Y. STAT signaling in mammary gland differentiation, cell survival and tumorigenesis. Mol Cell Endocrinol 2014;382(1):560-9.

66. Song J, Sapi E, Brown W, Nilsen J, Tartaro K, Kacinski BM, et al. Roles of Fas and Fas ligand during mammary gland remodeling. J Clin Invest 2000;106:1209-20.

67. Sohn BH, Moon HB, Kim TY, Kang HS, Bae YS, Lee KK, et al.
Interleukin-10 up-regulates tumour-necrosis-factor-alpha-related apoptosis-inducing ligand (TRAIL) gene expression in mammary epithelial cells at the involution stage. Biochem J 2001;360(17):31-8.

68. Schorr K, Li M, Bar-Peled U, Lewis A, Heredia A, Lewis B, et al. Gain of Bcl-2 is more potent than bax loss in regulating mammary epithelial cell survival in vivo. Cancer Res 1999;59(11):2541-5.

69. Walton KD, Wagner KU, Rucker EB $3^{\text {rd }}$, Shillingford JM, Miyoshi K, Hennighausen L. Conditional deletion of the bcl-x gene from mouse mammary epithelium results in accelerated apoptosis during involution but does not compromise cell function during lactation. Mech Dev 2001;109(2):281-93.

70. Atabai K, Fernandez R, Huang X, Ueki I, Kline A, Li Y, et al. Mfge8 is critical for mammary gland remodeling during involution. Mol Biol Cell 2005;16(12):5528-37.

71. Hanayama R, Nagata S. Impaired involution of mammary glands in the absence of milk fat globule EGF factor 8. Proc Natl Acad Sci U S A 2005;102(46):16886-91

72. Seymour T, Twigger AJ, Kakulas F. Pluripotency genes and their functions in the normal and aberrant breast and brain. Int $\mathrm{J}$ Mol Sci 2015;16(11):27288-301.

73. Boras-Granic K, Dann P, Wysolmerski JJ. Embryonic cells contribute directly to the quiescent stem cell population in the adult mouse mammary gland. Breast Cancer Res 2014;16(6):487.

74. Hynes NE, Watson CJ. Mammary gland growth factors: Roles in normal development and in cancer. Cold Spring Harb Perspect Biol 2010;2(8):a003186.

75. Schwertfeger KL. Fibroblast growth factors in development and cancer: Insights from the mammary and prostate glands. Curr Drug Targets 2009;10(7):632-44.

76. Kahata K, Maturi V, Moustakas A. TGF- $\beta$ family signaling in ductal differentiation and branching morphogenesis. Cold Spring Harb Perspect Biol 2017. pii: a031997.

77. Mapes J, Li Q, Kannan A, Anandan L, Laws M, Lydon JP, et al. CUZD1 is a critical mediator of the JAK/STAT5 signaling pathway that controls mammary gland development during pregnancy. PLoS Genet 2017;13(3):e1006654

78. Loladze AV, Stull MA, Rowzee AM, Demarco J, Lantry JH $3^{\text {rd }}$, Rosen CJ, et al. Epithelial-specific and stage-specific functions of insulin-like growth factor-I during postnatal mammary development. Endocrinology 2006;147(11):5412-23.

79. Schroeder JA, Lee DC. Dynamic expression and activation of ERBB receptors in the developing mouse mammary gland. Cell Growth Differ 1998;9(6):451-64

80. Watson CJ. Involution: Apoptosis and tissue remodeling that convert the mammary gland from milk factory to a quiescent organ. Breast Cancer Res 2006;8(2):203

81. Haan C, Kreis S, Margue C, Behrmann I. Jaks and cytokine receptors - An intimate relationship. Biochem Pharmacol 2006;72(11):1538-46.

82. Wilson GJ, Hewit KD, Pallas KJ, Cairney CJ, Lee KM, Hansell CA, et al. Atypical chemokine receptor ACKR2 controls branching morphogenesis in the developing mammary gland. Development 2017;144(1):74-82.

83. Kessenbrock K, Smith P, Steenbeek SC, Pervolarakis N, Kumar R, Minami Y, et al. Diverse regulation of mammary epithelial growth and branching morphogenesis through noncanonical Wnt signaling. Proc Natl Acad Sci U S A 2017;114(12):3121-6. 